\title{
GROWTH AND DEVELOPMENT OF THE VENTRICULAR MYOCARDIUM FROM BIRTH TO ADULT LIFE*
}

\author{
BY \\ SIXTO RECAVARREN AND JAVIER ARIAS-STELLA \\ From the Department of Pathology, Universidad Peruana de Ciencias Médicas y Biológicas, Lima, Perú \\ Received July 29, 1963
}

Uniformity of opinion regarding the changes that occur in the weight of the right ventricle after birth has not been reached yet. Thus, while Müller (1883) and Keen (1955) described the occurrence of postnatal atrophy of the muscular mass of the right ventricle, Emery and Mithal (1961) found no evidence of such atrophy. According to them the right ventricle increases in weight from birth but more slowly than the left. One of the points at issue is whether, at the time of birth, the weight .of the right ventricle is equal to, greater than, or less than the weight of the left ventricle (Müller, 1883; Keen, 1955; Emery and Mithal, 1961; Sala Panisello et al., 1958; Emery and MacDonald, 1960). The confusion is partly due to the limited number of cases studied by some investigators: some series have included, in the same group, cases whose ages correspond to different stages in the evolution of the cardiac mass and also some newborn infants with abnormally low body weight.

In order to solve this problem it is necessary to determine the ventricular weights at the time of birth. This knowledge should be derived from the study of a sufficiently large series of stillborn infants, excluding any who are premature or who have an abnormal body weight.

In the present report, the weight of both ventricles in newborn infants, and the evolution of the ventricular weight from the first day of life to the eighth decade have been studied.

\section{MATERIAL AND MethodS}

In the present series, 165 hearts of subjects whose ages ranged between stillborn and 80 years were studied. All were born at, and remained throughout life at, sea-level.

The stillborn cases were collected from the Hospital de la Maternidad de Lima and fulfilled the following essential requirements: (1) full-term delivery; (2) body weight between 3000 and 4500 g. (mean $3547 \mathrm{~g}$.); (3) death due to intrauterine asphyxia; and (4) absence of congenital abnormalities.

The rest of the cases were studied at the Morgue Central de Policía and at the Hospital del Niño of Lima. All had a body weight within the limits considered normal for their ages, and had died from accidents or acute infections. Cases with congenital malformations were not included.

The cases were divided into five groups. Group 1, stillborn infants (31 cases); Group 2, subjects aged 1 to 15 days ( 11 cases); Group 3, subjects aged 16 days to 4 months (30 cases); Group 4, subjects aged 5 months to 4 years ( 35 cases), and Group 5, subjects aged 15 to 80 years (45 cases).

The small number of cases in Group 2 is due to the difficulty of obtaining cadavers with a normal body weight. For the calculation of the percentage weight of the right ventricle in relation to the total ventricular weight, 13 infants, who died from dehydration with diminished cardiac weight, were also studied. The values obtained in these were not different from those found in the other 11 infants.

In Groups 4 and 5, all ages between 5 months and 80 years were more or less homogeneously represented.

The heart cavities were packed with cotton soaked in formalin, and the organs were immersed in 10 per cent formaldehyde for three to four days. After fixation, the atrial mass was dissected from the ventricles, and the epicardial fat, coronary vasculature, and valves were removed by sharp dissection.

With a ruler lying posteriorly, the distance from the atrio-ventricular sulcus to the apex was divided

* Supported by United States Public Health Service Grant H-7000 and by Public Health Grant 8576. 
TABLE I

The Weights of the Right and Left Ventricles at Various Stages from Birth to Adult Life

\begin{tabular}{|c|c|c|c|c|c|c|c|}
\hline Group & Age & $\begin{array}{c}\text { Number } \\
\text { of } \\
\text { cases }\end{array}$ & $\begin{array}{l}\text { Body weight } \\
\text { (g.) }\end{array}$ & $\begin{array}{l}\text { Total ventricular } \\
\text { weight (g.) }\end{array}$ & $\begin{array}{l}\text { Right ventricular } \\
\text { weight (g.) }\end{array}$ & $\begin{array}{l}\text { Left ventricular } \\
\text { weight (g.) }\end{array}$ & $\begin{array}{c}\text { Ratio of } \\
\text { right } \\
\text { ventricle to } \\
\text { total }(\%)\end{array}$ \\
\hline 1 & Stillborn & 31 & \multirow{4}{*}{$\begin{array}{c}3000-4500 \\
\text { (mean 3547) } \\
3023-4100 \\
\text { (mean } 3417) \\
3600-6500 \\
\text { (mean 4466) } \\
\text { - }\end{array}$} & $16 \cdot 17$ (S.D. $2 \cdot 25$ ) & $9 \cdot 15$ (S.D. $1 \cdot 10)$ & $7 \cdot 02$ (S.D. 1.34) & $56 \cdot 25$ \\
\hline 2 & 1-15 days & 11 & & $16 \cdot 66$ & $8 \cdot 05$ & $8 \cdot 61$ & $47 \cdot 75$ \\
\hline 3 & 16 days -4 months & 30 & & $18 \cdot 27$ & 6.96 & $11 \cdot 31$ & $37 \cdot 70$ \\
\hline 4 & 5 months -4 years & 35 & & 33.47 & $11 \cdot 54$ & 21.93 & $34 \cdot 02$ \\
\hline 5 & $5-80$ years & 45 & - & $119 \cdot 4$ & 44.02 & $75 \cdot 38$ & $36 \cdot 13$ \\
\hline
\end{tabular}

into five equal parts: at these points the heart was sectioned at right angles to its greater diameter from the posterior aspect to the anterior, resulting in five blocks of identical thickness. These were designated S1, S2, S3, S4, and S5.

In each of the blocks the right ventricular portion was dissected from the left, following the method of Lewis (1914) and Herrmann and Wilson (1922). The weight of the total ventricular mass, the weight of the right ventricle, the weight of the left ventricle, and finally the weight of the right ventricle expressed as a percentage of the total ventricular weight, were obtained. At the time of dissection and weighing, data relating to the history or derivation of each case were unknown. The method used has been described in detail elsewhere (Arias-Stella and Recavarren, 1962). Owing to the natural process of growth the mean values of total ventricular, right ventricular, and left ventricular weights and percentage of right ventricular

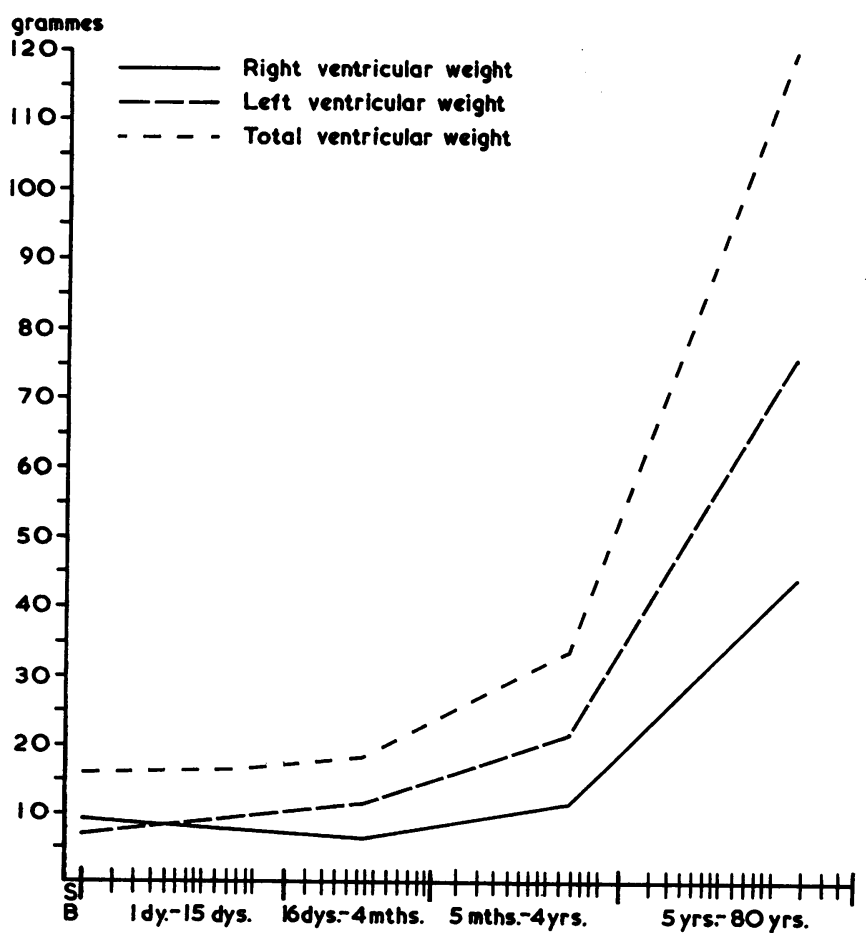

Fig. 1.-Evolution of the weights of the right and left ventricles and of the total ventricular mass. 
weight obtained in each group do not necessarily represent a mean of the normal weight corresponding to the various ages included in each group, but they have been indicated because they help to draw the curve of evolution of the myocardial weight from birth to adult life.

\section{RESULTS}

The results are summarized in Table I and Fig. 1. The values obtained show a progressive increase of total ventricular weight beginning immediately after birth. During the first stages, the increment in weight is slight but after the fifth month of life it is remarkable.

The left ventricular muscle mass increases in weight continuously from birth, following a curve

TABLE II

Comparative Values of the Right Ventricular Weight in Stillborn and Subjects from 16 Days to 4 MONTHS OF AgE

\begin{tabular}{|c|c|c|c|c|c|}
\hline & & No. of cases & Mean \pm S.E. & S.D. & Extreme values \\
\hline $\begin{array}{l}\text { Stillborn } \\
16 \text { days to } 4 \text { months } \ldots\end{array}$ & $\begin{array}{ll}. & . . \\
. & . .\end{array}$ & $\begin{array}{l}31 \\
30\end{array}$ & $\begin{array}{l}9 \cdot 1516 \pm 0 \cdot 197 \\
6 \cdot 9666 \pm 0 \cdot 187\end{array}$ & $\begin{array}{l}1.099 \\
1.027\end{array}$ & $\begin{array}{l}7 \cdot 8-12 \cdot 1 \\
5 \cdot 4-9 \cdot 0\end{array}$ \\
\hline & $t$ value & & & 8.0242 & \\
\hline
\end{tabular}

$\mathrm{p}<0.001$.

$t$ values calculated by Fisher's $t$ test

more or less parallel to that of the total ventricular weight. Thus the increase is very slight until the fourth month but becomes greater after this.

The study of the evolution of the right ventricular weight clearly demonstrates that immediately after birth there is a progressive decrease in the weight of the muscular mass of the right ventricle. This decrease is greater between the sixteenth day and the fourth month of life. A reduction of as much as 23.9 per cent of the original weight occurs during this period. The comparative analysis of the mean of the right ventricular weight at birth with the mean right ventricular weight of the cases between 16 days and 4 months shows a difference that is statistically significant, $\mathrm{p}<0.001$ (Table II and Fig. 2). This curvilinear regression of the right ventricular weight in relation to age has been traced, using a second degree parabola $\left(y=a x^{2}+b x+c\right)$ and the least squares method (Snedecor, 1956; Waugh, 1952). The regression equation obtained was: $y=0.07 x^{2}$ $+0.39 x+7 \cdot 19$ (Fig. 3). After the fifth month, there is an increase in the weight of the right ventricle. During the period between the fifth month and the fourth year this increase is slight, but after the fifth year it is greater. In Fig. 3, which shows the individual values, it can be seen that the right ventricle does not regain its weight at birth until the age of 7 months.

Finally we should refer to the values found in the percentage of the right ventricular weight in relation to the total ventricular weight. At birth the right ventricle is heavier than the left (Fig. 4). From 1 to 15 days of age, the percentage weight of the right ventricle decreases from 56.25 to 47.75 per cent. The predominance in weight of the left ventricle begins about the seventh day of life. Between the sixteenth day and the fourth month of life the percentage of the right ventricle weight continues to decrease becoming 37.7 per cent at the end of this period. The fall in the percentage of weight of the right ventricle in relation to the total ventricular weight in this period results from two factors: one is the diminution in weight of the right ventricle, and the other the increase in the weight of the left ventricle. The lowest percentage weight of the right ventricle, 34.02 per cent, is reached between the fifth month and the fourth year of life. Since during this period the weight of the right ventricle is increasing this fall is due exclusively to the increase in weight of the 

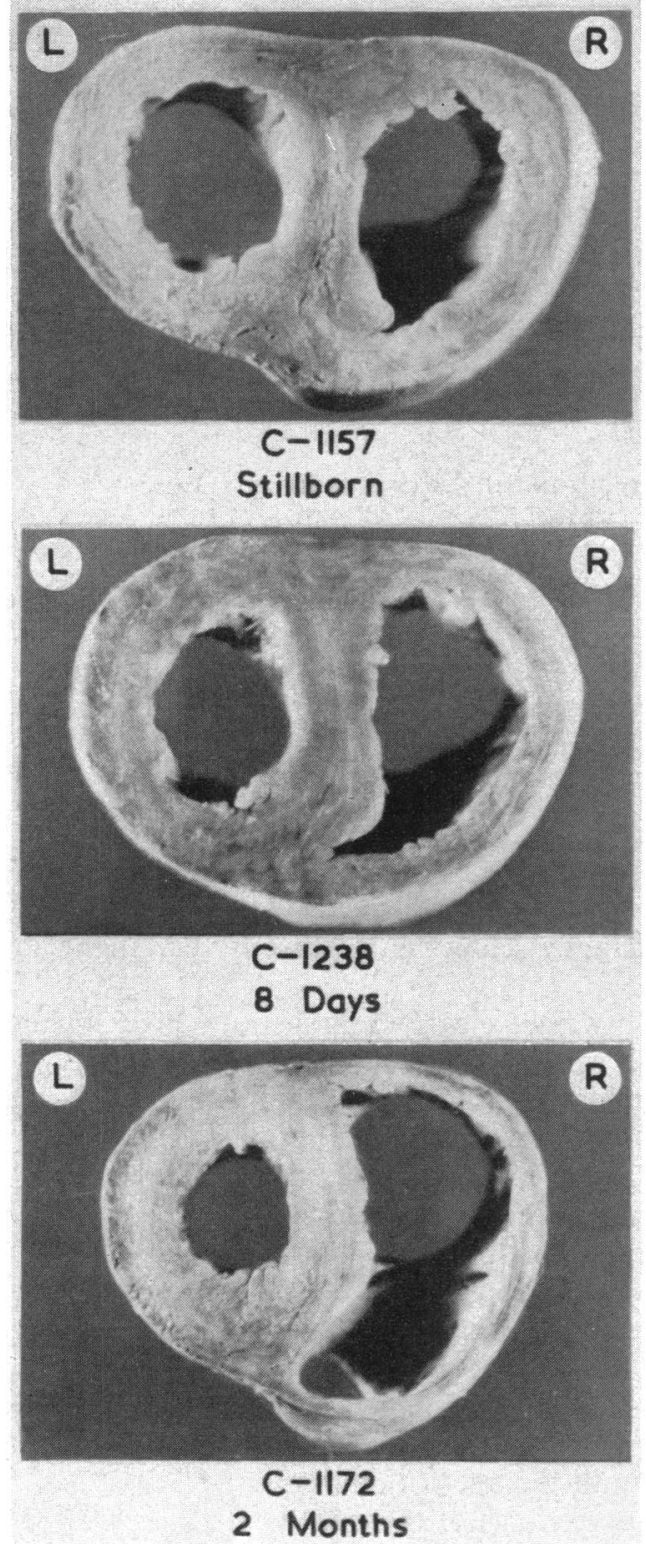

FIG. 2.-The gross appearance of the ventricles at section $\mathrm{S} 1$ in three different age-groups is shown. $R$ : right ventricle, $L$ : left ventricle.

Top stillborn group, clearly demonstrates the muscular development of the right ventricle. Middle is from an infant 8 days old in whom a lesser development of the right ventricular mass, in comparison with the case at Top, can be noticed. Bottom is from a 2-month-old infant in whom the thinning of the right ventricular walls and the obvious preponderance of the left ventricle is easily evident. left ventricle. In subjects over 5 years of age, the percentage of the right ventricular weight in relation to the total ventricular weight increases slightly. The fact that the increase in total ventricular weight up to the fourth month of life is so slight is due to the decrease in weight of the right ventricle during this period. The greater increase in total ventricular weight from the fifth month on is due, primarily, to the rapid increase in weight of the left ventricular mass. During the period from the fifth month to the fourth year, the increase in weight of the left ventricle greatly surpasses that of the right ventricle.

\section{Discussion}

The present study has established that, at birth, the weight of the right ventricle is greater than that of the left ventricle. This can be explained on the basis of the characteristics of fotal circulation. During fœtal life, the right ventricle has a greater burden than the left. The right heart not only supplies the pulmonary circulation but also, through the ductus arteriosus, a large part of the systemic circulation. Evidently this represents an extra load for the right ventricle. Furthermore, it is well known that the resistance in the fotal pulmonary circulation is high. Assali, Sehgal, and Marable (1962) have demonstrated, in the lamb, that during fotal life the pressure in the pulmonary artery is greater than that in the aorta. Before birth, the left ventricle is responsible only for the maintenance of a part of the systemic circulation. The different development reached by the ventricular masses at the moment of birth is a consequence of the dissimilarity of the muscular work performed during fœtal life.

We have also established that during the first months of life there is a diminution in the weight of the right ventricle. The postnatal hæmodynamic changes serve to explain this phenomenon. Born et al. (1954), Dawes (1961), and Assali et al. (1962) have demonstrated, in lambs, that at birth the ligation of the umbilical cord and the sudden expansion of the vascular pulmonary bed, lead to a rapid fall in pulmonary blood pressure. Moreover, after birth, as a consequence of the greater oxygen saturation of the blood, and the effect of nervous reflexes, the calibre of the ductus arteriosus is considerably reduced (Born et al., 1956; Eldridge and Hultgren, 1955; Dawes, Mott, and Widdi- 


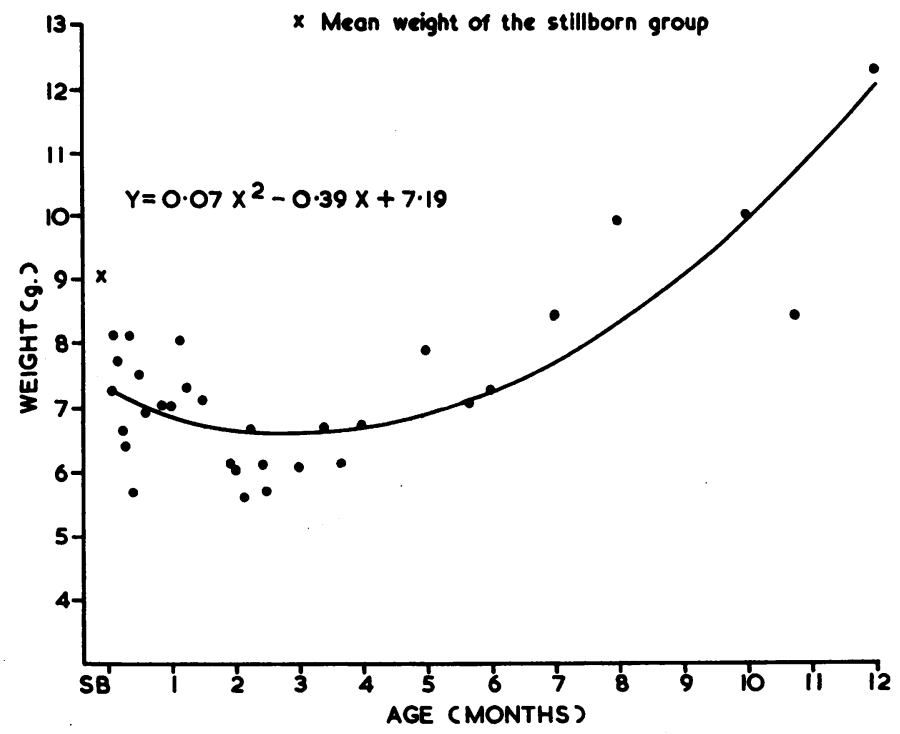

FIG. 3.-Curvilinear regression of the right ventricular weight in relation to age.

combe, 1955). These two events create a new hæmodynamic situation that results in a lesser load for the right ventricle.

Emery and Mithal (1961) expressed the view that the results of Keen (1955), which indicated atrophy of the right ventricle after birth, were invalid because he had included in his series wasted

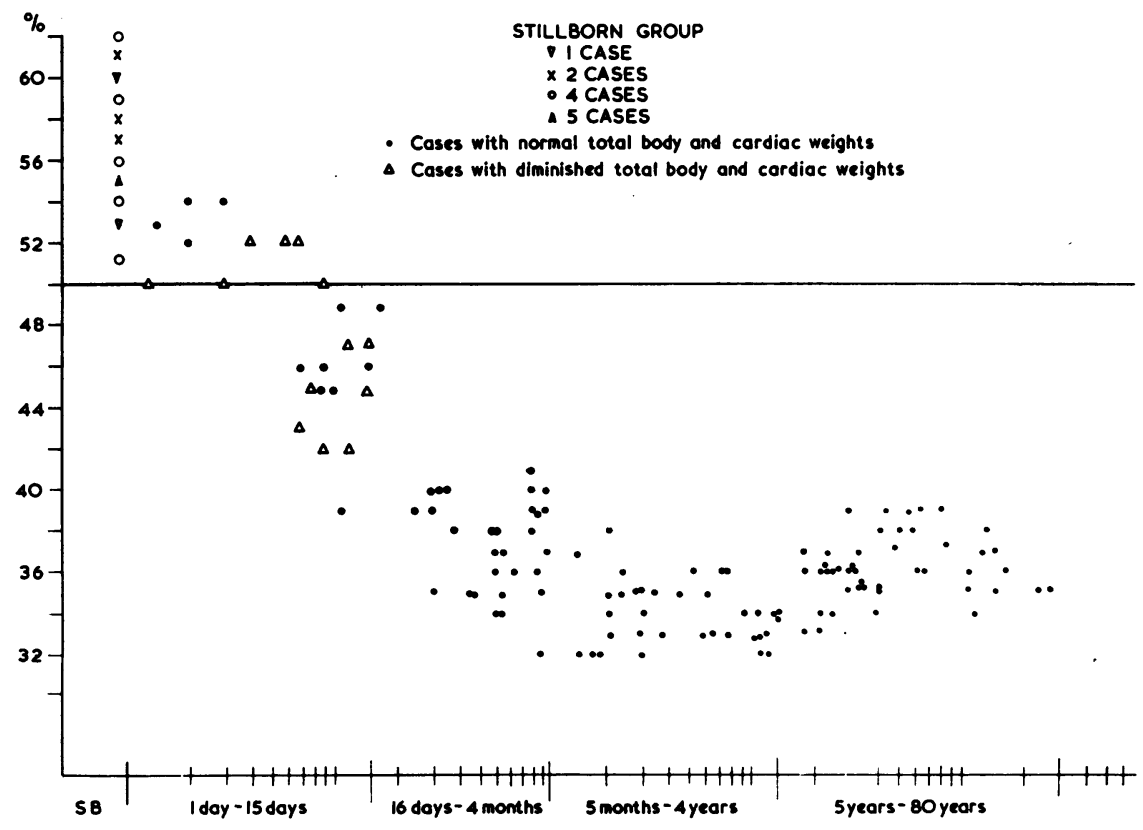

Fig. 4.-Percentage of the right ventricular weight in relation to total ventricular weight, from stillborns to the eighth decade of life. 
children or subjects with abnormal body weight. This criticism cannot be levelled against our results, since only children of normal body weight were included in our study. Furthermore no relation has been obtained when the right ventricular weight of the cases up to the fourth month of life were plotted against the body weights $(r=0 \cdot 30)$. Conversely when the right ventricular weight was charted against the ages an inverse relation was found up to the fourth month of life. After the fifth month of life this relation becomes direct. From the fifth month of life to 11 years the statistical study of this relation is highly significant $(r=0.99)$.

Our findings agree closely with the changes in the electrocardiogram and vectorcardiograms during the postnatal period, described by Peñaloza et al. (1960) in normal infants living at sea-level. These workers showed that at birth there was right ventricular preponderance, but this decreased during the first days of life so that at the end of the first week left ventricular preponderance was starting to emerge.

\section{SUMMARY}

The evolution of the total ventricular weight, the weight of the right and left ventricles, and the percentage of the right ventricular weight in relation to the total ventricular weight have been studied in the hearts of 165 normal subjects born and living at sea-level, from birth up to the age of 80 years.

We have shown that up to the age of 7 days, the right ventricle weighs more than the left. From birth the weight falls progressively until the fourth month of life. It then begins to increase again, surpassing its birth weight at approximately the eighth month. These findings are discussed in relation to the hæmodynamic changes that take place in the circulation at birth.

We express our thanks to Dr. Ramón Criado chief of the Morgue Central de Policia de Lima, to Dr. José Pereda pathologist of the Hospital de la Maternidad de Lima to Dr. Gerardo Boisset, and to Dr. Manuel Muro pathologists of the Hospital del Niño de Lima. The help of Mr. Julio Cruz and Dr. Carlos Monge C. in the statistical study is greatly appreciated.

\section{REFERENCES}

Arias-Stella, J., and Recavarren, S. (1962). Right ventricular hypertrophy in native children living at high altitude. Amer. J. Path., 41, 55.

Assali, N. S., Sehgal, N., and Marable, S. (1962). Pulmonary and ductus arteriosus circulation in the fetal lamb before and after birth. Amer. J. Physiol., 202, 536.

Born, G. V. R., Dawes, G. S., Mott, J. C., and Rennick, B. R. (1956). The constriction of the ductus arteriosus caused by oxygen and by asphyxia in newborn lambs. J. Physiol. (Lond.), 132, 304. ,$- \frac{F}{\text { Fetus } ; \text { Physiological Aspects of Development. Cold Spr. Harb. Symp. quant. Biol., 19, 102. }}$, In the Mammalian

Dawes, G. S. (1961). Changes in the circulation at birth. Brit. med. Bull., 17, 148. , Mott, J. C., and Widdicombe, J. G. (1955). The patency of the ductus arteriosus in newborn lambs and its physiological consequences. J. Physiol. (Lond.), 128, 361.

Eldridge, F. L., and Hultgren, H. N. (1955). The physiologic closure of the ductus arteriosus in the newborn infant. J. clin. Invest., 34, 987.

Emery, J. L., and MacDonald, M. S. (1960). The weight of the ventricles in the latter weeks of intra-uterine life. Brit. Heart J., 22, 563.

$\overline{\text {, }}$, and Mithal, A. (1961). Weights of cardiac ventricles at and after birth. Brit. Heart J., $23,313$.

Herrmann, G. R., and Wilson, F. N. (1922). Ventricular hypertrophy: A comparison of electrocardiographic and postmortem observations. Heart, 9,91 .

Keen, E. N. (1955). The postnatal development of the human cardiac ventricles. J. Anat. (Lond.), 89, 484.

Lewis, T. (1914). Observations upon ventricular hypertrophy, with especial reference to preponderance of one or other chamber. Heart, 5, 367.

Müller, W. (1883). Die Massenverhältnisse des menschlichen Herzens. Voss, Hamburg and Leipzig.

Peñaloza, D., Gamboa, R., Dyer, J., Echevarría, M., and Marticorena, E. (1960). The influence of high altitudes on the electrical activity of the heart. I. Electrocardiographic and vectocardiographic observations in the newborn, infants, and children. Amer. Heart J., 59, 111 .

Sala Panisello, F., Castellanos, A., Junco, J. A., and Valladares, F. (1958). Medidas significativas en el corazón del prematuro. I. Re-evaluación de un método eficaz para determinar el peso real de los ventrículos. Rev. cuba.
Pediat., 30, 19 .

Snedecor, G. W. (1956). Statistical Methods, 5th ed. The Iowa State College Press, Ames, Iowa.

Waugh, A. E. (1952). Elements of Statistical Method, 3rd ed. McGraw-Hill, New York, Toronto, London. 